\title{
Coordenadas teóricas para pensar el discurso periodístico sobre política
}

Theoretical coordinates to think the journalistic discourse on politics

\author{
Yanela Soler Más ysolermas64@gmail.com \\ https://orcid.org/0000-0002-7802-5465 \\ Universidad de La Habana (Cuba)
}

\section{Resumen}

El artículo aborda la relación entre la comunicación política, el discurso periodístico y los conceptos de agenda setting y la tematización. Reflexiona sobre el vínculo de la prensa con el sistema político, que posibilita el cumplimiento de funciones orientadas a la formación de la opinión pública y la construcción de la hegemonía mediante la puesta en práctica de técnicas de comunicación política que encuentran eco en el discurso periodístico y, durante los 
procesos electores, contribuye a reforzar y/o deslegitimar actitudes de los bandos contendientes a través de estrategias discursivas que propician la generación de opinión sobre el tema político.

Palabras clave: Discurso periodístico; política; agenda mediática; tematización.

\section{Abstract}

The article addresses the relationship between political communication, journalistic discourse and the concepts of agenda setting and thematization. Reflect on the link between the press and the political system, which enables the fulfillment of functions aimed at the formation of public opinion and the construction of hegemony through the implementation of political communication techniques that are echoed in the journalistic discourse and, during the electoral processes, it contributes to reinforce and / or de-legitimize attitudes the contending sides through discursive strategies that propitiate the generation of opinion on the political issue.

Keywords: Journalistic discourse; politics; media agenda; thematization.

Grossi (1985) refiere que la comunicación política es "resultado de un complejo proceso de transacciones que se manifiesta en un campo o ámbito específico caracterizado por las interrelaciones estables entre dos subsistemas: los partidos y los mass media" (p. 148). Luhmann (1975) complementa este planteamiento, al comprenderla como la forma de generalización simbólica de la dimensión político-partidista en un ambiente massmediatizado. De esta forma, los productos comunicativos resultantes están mediados tanto por las lógicas e intereses del partido político como por los de la institución comunicativa.

Tomando en consideración lo anterior, Mazzoleni (1998) indica la existencia de una comunicación política orientada a las funciones partidistas y otra a los medios. En el primer 
caso, se encamina a reforzar la identidad de los militantes y simpatizantes del partido; mientras que en el segundo, los medios de comunicación "contribuyen considerablemente a ilustrarla, a filtrarla, aunque bajo la perspectiva particular del consumo y del espectáculo político" (Grossi, 1985: 152).

Como mediadores de lo simbólico en lo político (Rositi, 1980), los medios provocan que la comunicación política esté integrada por varios niveles que Moragas (1979) enumera como: sistemas de comunicación no propagandísticos reguladores de los flujos organizativos de la actividad política y administrativa; uso de la industria cultural con fines políticos; mantenimiento de una conducta adecuada al 'statu quo' político y económico; empleo de recursos comunicativos opuestos al poder establecido y procesos de persuasión política como referendos, elecciones o campañas de sensibilización.

En este contexto, la seducción pública de los medios aumenta la exigencia por parte de los políticos de recurrir a ellos para mantener su contacto con el electorado. Esto se sustenta en Rincón cuando refiere que "habitamos una democracia mediática, una política del espectáculo y una gobernabilidad que se juega en encuestas de favorabilidad; porque comunicación y política son juegos de afectos y celebraciones del ego" (2010: 6).

El pragmatismo de la ciencia política se preocupa por los efectos de la comunicación política a través de los medios particularmente en los procesos electorales. Sartori plantea al respecto que

el poder electoral en sí es la garantía mecánica de la democracia; pero las condiciones bajo las cuales el ciudadano obtiene la información y está expuesto a las presiones de los fabricantes de opinión son las que constituyen la garantía sustantiva (1992: 263).

Semejante planteamiento corrobora el rol de los medios como formadores de opinión pública y constructores de hegemonía, al estructurar la visibilidad y la posible influencia política de los actores y grupos sociales.

Hace poco más de setenta años, durante el periodo de campaña presidencial en Estados Unidos, Lazarsfeld y Berelson (1944) analizan el papel de la prensa impresa y la radio entre los votantes del Condado de Eire. Entendiendo las campañas electorales como "el proceso de planificar y ejecutar actividades con la intención de ganar votos" (1944), los investigadores 
concluyeron que los medios no habían sido trascendentes en la formación de la opinión del electorado, pero sí reforzaron sus actitudes y su comportamiento.

Luego de estos resultados, a juicio de Kraus y Davis (Beaudoux y D'Adamo, 2004), hubo un periodo en que los medios de comunicación fueron prácticamente ignorados como agentes de socialización política entre los estudiosos de esta corriente, hasta fines de los 60 . Sin embargo, hacia los ochenta Artenton (1987) destaca que las campañas electorales utilizan los recursos de comunicación para enviar mensajes persuasivos a un amplio electorado, con el fin de incrementar el número de votos el día de las elecciones.

Mucho se ha discutido en torno a la influencia de las campañas en la intención de voto. Los estudios desarrollados se centran en el efecto de los medios sobre la opinión pública. Al respecto, los científicos sociales argentinos Beaudoux y D'Adamo argumentan que "el consenso de los investigadores apunta a señalar que los medios de comunicación se han transformado en corazón y sistema nervioso de los escenarios políticos, en particular de los de campaña" (2004: 8).

La mayoría de los análisis se condensan en primer lugar, en los patrones de exposición a los medios y cómo los públicos usan la información política a la que se exponen y en segundo lugar, en la cobertura informativa al proceso electoral. Sin dudas, la primera vertiente hace pensar en el fenómeno de la opinión pública, pues al ser los medios responsables de la construcción de lo simbólico y de la fabricación del consenso, trasmiten los resultados de los sondeos de opinión sobre temas políticos para influir en la esfera pública.

Luhmann (1978) considera que la opinión pública es una estructura selectiva de temas de la Comunicación Política y le asigna la función de mecanismo guía entre los procesos de comunicación pública, las demandas sociales y las respuestas de su sistema político. NoelleNeumann (1995) aporta en este sentido la teoría de la espiral del silencio, que define a la opinión pública como control social y a los medios como el sitio del que disponen las audiencias para observar el clima de opinión. Según la autora, las personas temen expresar su verdadera opinión cuando prevalece la de la mayoría, y los medios proporcionan la visibilidad de las tendencias de opinión confrontadas. Pero, aun cuando se legitimen las opiniones a través de ellos, su influencia

es predominantemente inconsciente. La gente no puede informar sobre lo que ha sucedido.

Más bien, mezcla sus propias percepciones directas y las percepciones filtradas por los ojos

Question, Vol. 1, N. ${ }^{\circ}$ 63, julio-septiembre 2019. ISSN 1669-6581

Instituto de Investigaciones en Comunicación | Facultad de Periodismo y Comunicación Social | Universidad Nacional de La Plata 
de los medios de comunicación en un todo indivisible que parece proceder de sus propios pensamientos y experiencias (...) (Noelle-Neumann, 1995: 221).

Con la teoría de la Espiral del Silencio se muestra la importancia de los medios en la dinámica social y en la generación de consenso, pues a través de ellos se socializan opiniones que se anuncian como irrefutables, a las que constantemente se sumarían adeptos, por temor a sentirse aislados. Sin embargo, Noelle-Neumann (1995) presenta su teoría de la opinión pública como un proceso universal, cuando en realidad esta dinámica puede diferir de un caso a otro, dependiendo de los tipos de temas y del balance de opiniones en juego.

Si en los momentos de elecciones las élites políticas evidencian más fuertemente sus contradicciones en las distintas esferas del debate público, el discurso de los medios de comunicación se hace eco de él y adopta posiciones más críticas. Moreno (2007) argumenta que los medios son instancias prioritarias de circulación y difusión social de los frames 0 marcos ideológicos de las élites de poder y constituyen espacios de selección y visibilidad de los problemas políticos de cada sociedad, habilitando en sus agendas issues coyunturales sobre los que emergen posiciones ideológicas.

En esta línea, mientras Ellis y Stimson (2005) observan que la exposición cotidiana a las noticias se constituye en pre-requisito para la influencia de las ideologías dominantes, Luhmann (2000) indica que la función de los medios es construir la memoria social a partir de la observación permanente de los fenómenos que ocurren en su interior, por la importancia que esto reviste para la autopoiesis del sistema social.

Ambas visiones hacen pensar entonces en que la constitución de los medios como grandes corporaciones de comunicación es un rasgo que condiciona su relación con el sistema político. En este sentido, llama la atención un fenómeno asociado con su intervención en el diseño de estrategias durante periodos de campaña. Beaudoux y D'Adamo sostienen que esto se debe a múltiples factores, siendo uno de ellos "la observable progresiva erosión de las identidades partidarias e ideológicas, que ya no actúan como determinantes del voto en la misma proporción en que lo hacían en décadas anteriores" (2004: 9).

Esto da lugar a una desalineación política, cuyas consecuencias se evidencian en que a diferencia de 1944, cuando las organizaciones partidarias protagonizaban los teatros de campaña, servían como conducto para comunicar informaciones y como medios para captar votos, las campañas actuales "acentúan los aspectos personalistas y pragmáticos, tienden a 
ser de evangelización más que de reafirmación de la fe" (Waisbord, 1995: 17) ante la realidad de que muchos ciudadanos no ofrecen una lealtad perpetua hacia los actores políticos 0 tendencias por los que votan.

La personalización de la política que se visualiza en las sociedades contemporáneas da lugar entonces a una decisión de voto centrada en el candidato, su imagen y sus propuestas, y como consecuencia los partidos ven disminuida su capacidad de movilización. Manin (1998) asegura en este sentido que la tendencia de los votantes es a decidir a favor o en contra de una persona, en lugar de hacerlo por un partido o programa.

Dicho fenómeno, conocido como "crisis de representación" alude a la representación política, con lo cual la relación entre los medios y la política se reduce de forma simplista a cómo aquellos sustituyen el rol de los partidos. García Delgado considera que crisis de representación es "la situación en la que se da la pérdida de confiabilidad en los partidos y en las grandes estructuras de mediación" (1998: 373). Con ello puede asegurarse que el rol de los medios se relaciona con los posibles vacíos que generan estas instituciones en la sociedad.

\section{Discurso periodístico y cuestiones de agenda}

De entre toda la amalgama de discursos que proponen los medios, el periodístico constituye un vehículo para transmitir información y opiniones e interpretar la realidad sobre la base de su construcción social, expresada no sólo en la representación de hechos, sino también por actos que sean asumidos como adecuados por los receptores y, a la vez, mediante opiniones relativas a los acontecimientos considerados verosímiles.

A partir de lo anterior, puede asegurarse que el discurso periodístico se constituye desde un "proceso compuesto de tres fases interrelacionadas: la producción, la circulación y el consumo o reconocimiento" (Rodrigo Alsina, 2005: 29) (1). Sin embargo, ese escenario que se fabrica es dinámico, complejo y mutable, por tanto, el discurso periodístico sólo muestra una de sus aristas, lo cual explica por qué se trata de una realidad socialmente construida.

Lo anterior se sustenta en Verón (1993) y en Rodrigo Alsina (2005), para quienes el acontecimiento social es la materia prima generadora de la noticia, pero no puede considerarse un objeto presente en cualquier fragmento de la realidad y cuyos aspectos los medios dan a 
conocer fielmente de inmediato porque "sólo existen si los medios los corroboran" (Verón, 1993: 11), los muestran y los analizan.

Desde una visión objetiva, Champagne (2000: 3) acierta, al destacar en este debate el carácter conveniente de la mediatización de un acontecimiento, pues se trata del resultado de una movilización espontánea o provocada de los medios en torno a un suceso que consideran importante durante determinado periodo de tiempo, atendiendo a su postura político-ideológica que incide en la intencionalidad de su línea editorial.

Por otro lado, si se repara en que la vida cotidiana se origina en los pensamientos y las acciones de los sujetos, puede comprenderse la subjetividad que prima en el proceso de conversión del acontecimiento en noticia: los individuos aportan sentido al suceso.

Ello indica que en la construcción material del discurso periodístico interviene un conjunto de subjetividades dependientes del contexto, de los modelos cognitivos del emisor en primera instancia y el receptor luego (mediaciones, experiencias, historias de vida personal) y de su capacidad para interpretar los acontecimientos devenidos noticia u otro género. $Y$, como destaca Calzadilla (2012), dichas mediaciones que pueden ser políticas y/o socioculturales, se articulan, interfieren y condicionan, unidas a otras de tipo tecnológico y ético-profesionales, que también deben ser tomadas en cuenta.

Esto lleva a pensar que el discurso periodístico es producto de una práctica social altamente especializada con peculiaridades concretas, por transmitirse a través de los medios de comunicación. Pero debe tenerse en cuenta además que el discurso periodístico posee una cualidad polifónica (Borrat, 1989; Rondoletto, 2001; Casado, 2008; Ricardo, 2012) e interdiscursiva, en tanto absorbe, articula o desecha otros discursos sociales con un carácter actual, público y social, en aras de construir, reportar y evaluar la realidad.

Cuando comienza a resaltarse el poder de la comunicación estratégica en los estudios sobre campañas electorales, se hace referencia a una serie de efectos cognitivos y de persuasión política. Así, el establecimiento de la agenda que describen McCombs y Shaw (1972), plantea condicionantes cognitivas que abarcan desde el proceso de producción informativa hasta la organización de los conocimientos que los receptores asumen como propios, al recibir los productos comunicativos.

De la misma forma en que los medios presentan los temas sobre los que debe gestarse determinada opinión, su jerarquización también establece sobre qué cosa pensar primero y 
sobre qué después. A través de las agendas se produce un impacto directo y acumulativo sobre los públicos, donde influye el ámbito cognoscitivo, aunque los medios tienen distinto poder para marcar agendas en quienes se exponen a ellos. Esto se evidencia al considerar los diferentes lenguajes periodísticos.

Numerosos autores (Sartori, 1992; Brussino; Paz García; Rabbia e Imhoff, 2011) aluden que el centro de la actividad proselitista lo tiene la televisión. No obstante, Fara (2004) y Brussino et al. (2011) coinciden en que si bien en algunos países, sobre todo latinoamericanos, la lectura de diarios resulta insignificante en comparación con el consumo de la televisión, ese medio tradicional detenta el mayor poder en fijar la agenda informativa, sin importar si se encuentra en soporte físico o digital.

Según un estudio realizado en 1972 sobre la campaña presidencial de Estados Unidos, los investigadores McClure y Patterson (Wolf, 2000: 90) concluyeron que aunque la televisión y la prensa impresa influyen de manera poderosa en las determinaciones de los públicos, las características de los programas informativos de la primera no permiten una eficacia cognoscitiva duradera; sin embargo, en la prensa impresa, la información se presenta a los lectores como relevante, constante y visible.

En este aspecto, McCombs sostiene que

los periódicos nos hacen llegar una multitud de pistas sobre la importancia, en términos relativos, de los temas de su agenda diaria. Esa noticia que abre la primera página, lo que va en portada comparado con lo que va en la página interior, el tamaño de un titular o incluso, la longitud de una noticia... todo eso nos está hablando de la relevancia de los temas de la agenda informativa. $Y$, en los sitios web, nos encontramos con pistas parecidas (2006: 24).

Los periódicos en cualquier soporte se muestran entonces como los organizadores de la agenda por excelencia, en tanto los otros medios, sobre la base de lo que los periódicos sacan a la luz, reconstruyen los temas de la agenda propuesta por aquellos.

Aunque es evidente el poder de los medios para fijar agendas en los públicos, lo cual constituye el nivel inicial de la formación de la opinión pública, no debe dejar de pensarse en las relaciones interpersonales que median muchas corrientes de pensamiento. La hipótesis de 
la agenda setting tiene en cuenta además los aportes de la teoría de las mediaciones sociales. Por tanto, su estructuración es un fenómeno de gran complejidad, que no solo abarca las planificaciones realizadas por un jefe de redacción o información de cualquier medio, sino que va más allá de las fronteras entre emisor y receptor.

Debe considerarse que los públicos no renuncian con facilidad a los temas que tienen predeterminados, y en los cuales piensan tradicionalmente, pero con el paso del tiempo incorporan otros a su subjetividad. Así, el llamado efecto de priming constituye otro de tipo cognitivo relacionado con sopesar las consideraciones al tomar una decisión y con los factores que influyen en las valoraciones de las personas.

Disímiles estudios (lyengar y Kinder, 1987; Krosnick y Kinder, 1990; lyengar y Simon, 1993) concluyen que los criterios con que las personas evalúan a los actores políticos o deciden su voto a una tendencia, son influidos por la cantidad de información que se produce sobre un tema determinado durante un periodo de campaña. Dichos resultados coinciden con McCombs y Evatt, para quienes "el establecimiento de la agenda es entonces un proceso que puede afectar tanto a los temas en que pensamos como a la forma en que pensamos sobre ellos" (1995: 30).

En las sociedades actuales, la sobreabundancia de aconteceres que se suceden a diario imposibilita que los medios los abarquen íntegramente en sus coberturas, por tanto, necesitan seleccionar qué sucesos compondrán la agenda. Esto sugiere que la interpretación que las audiencias realicen de un fenómeno de la realidad dependerá de la explicación que sobre el tema hallen en los medios. Este fenómeno, conocido como efectos de encuadre (framing) sugiere que los públicos, como los medios, enmarcan las noticias que llaman su atención mediante esquemas interpretativos que les permiten identificar la información proveniente de la realidad. Beaudoux y D'Adamo (2004) sostienen que ello "da paso a un proceso por el que la audiencia recoge los datos y los entrelaza en una narrativa que incluye una explicación causal, que a su vez servirá de parámetro para otras historias informativas y para dar sentido a un tema" (p. 12).

En la mayoría de los casos, se compensa el encuadre que los medios hacen de la información presentada con el de las audiencias, en consonancia con el paquete informativo. Sin embargo, no solo el factor de la necesaria omnipresencia de los medios impide que todos los acontecimientos ocurridos en la realidad social tengan protagonismo o presencia en ellos, sino también el hecho de que en muchas ocasiones son las instituciones de la política o la sociedad civil quienes determinan las agendas. Para Wolf (2002) estas "funcionan como lugar de paso 
para un material informativo sobre el que la selección periodística pierde progresivamente capacidad de decisión autónoma, de relevancia periodística que no sea solo de mercado u orientada a la concurrencia".

La lógica que se mueve en el mundo actual en la cuestión de la agenda informativa es: el entorno propone y el medio dispone. Este realiza una revisión estratégica de los campos de noticias que deben ser cubiertos por los reporteros, valorando en cada caso su pertinencia e impacto social.

Como transmisores de ideologías de cualquier índole, las agendas de los emisores de noticias de la prensa se materializan en discursos que responden a los intereses de las empresas comunicativas a las que los medios pertenecen. Por ello los estudios del discurso resultan de importancia para profundizar en cómo se elaboran los productos comunicativos y las estrategias discursivas de las que se valen para generar opinión pública.

Algunas consideraciones en torno a la tematización de la política en el discurso periodístico

Existen autores (López-Escobar, Llamas y McCombs, 1996; McCombs, 1996) que coinciden en que la teoría de la agenda setting consolida un método empírico para mostrar cómo los medios transfieren a sus audiencias las listas jerarquizadoras de los temas o problemas más destacados para la sociedad, la hipótesis ha sido denominada de diversas formas como resultado de la traducción del concepto a la lengua española: "función del establecimiento de la agenda temática", "jerarquización de noticias", "canalización periodística de la realidad" o "fenómeno de la tematización".

El último término expuesto irrumpe de las reflexiones de Luhmann (1978) y lo ha seguido Rositi (1982) quien lo entiende como el proceso de definición, establecimiento y debate público de los grandes temas políticos que los medios de comunicación han determinado.

Según Roda (1989), Dader (1990) y Rodríguez (2004) puede hablarse indistintamente de agenda setting y tematización; Saperas (1987) insiste en que son dos elementos diferentes aunque relacionables; mientras Agostini (1984), Badía (1992), De Fontcuberta (1993), Santillán 
(2005) y Túñez y Guevara (2009) sostienen que la tematización es una línea mejor elaborada y articulada que la de la agenda setting, por consistir en "un tratamiento a profundidad de los grandes temas que concentran la atención pública y movilizan a determinados grupos para imponer soluciones políticas" (Santillán, 2005).

Si al hablar de agenda setting se hace referencia implícitamente a tres tipos de agendas interrelacionadas: la de los medios, la pública y la política, entonces la tematización no solo depende de que un asunto se incluya en la agenda temática, sino que "llegue a ser definido y evaluado como un problema digno de entrar en la agenda política, lo cual da paso a la discusión de propuestas y a la selección de las que considera más adecuadas" (Chavero; González; Bouza; Castromil y Rodríguez, 2013: 4).

De manera que la tematización constituye un dispositivo de la información periodística que, a intervalos, interpreta, orienta o registra la realidad. Este proceso se apoya en las estrategias editoriales, en la línea política y en el contenido cualitativo de los medios de comunicación (Badía, 1992: 218).

Al tomar como base el principio de la tematización, puede entenderse que lo político tendrá "una tematización periodística si se presenta como un conflicto social, origina una discusión pública y logra soluciones" (Santillán, 2005). Con la presencia de un tema político en los medios se enfatiza su importancia, atendiendo a la actualidad y a "la jerarquía que se establece entre las distintas narraciones que conforman el discurso informativo. Se tematiza al incorporar el asunto a la agenda de los medios, pero el ciclo se cierra cuando ese tema pasa a la agenda del ciudadano como individuo y a la suma de ciudadanos como colectividad social" (Túñez y Guevara, 2009: 3).

El discurso periodístico, como espacio de expresión de esa conflictividad política, contribuye sin dudas a formar corrientes de opinión sobre este particular, por lo que el proceso de tematización periodística "permite estudiar el discurso informativo no simplemente como una realidad noticiosa sino como un espacio de interacción entre múltiples actores sociales en torno a la deliberación y solución de un conflicto social” (Santillán, 2005).

De hecho, los medios recogen los temas políticos relevantes para la sociedad y los presentan en forma de noticia para luego profundizar con el concurso de otros géneros. Pero como señala Rodrigo Alsina (1989), al "hablar de tematización habría que situarse al nivel del sistema informativo en general. Un tema repetido por distintos medios entra en el círculo de atención pública por el efecto de adición o de eco" (p. 136). 
Sobre este asunto, Santillán (2005) refiere que al suponer una disputa, la tematización de la política en la prensa "se presta a los objetivos del periodismo de opinión". El autor sustenta la idea debido a que cuando el tema sale a la luz, se manifiestan las posturas políticas en la producción editorial, originando la tematización periodística. La prensa cumple su función de seleccionar los temas, concentrar la atención sobre un individuo o una solución y precisar valoraciones.

Sin embargo, asumir la tematización política como exclusiva del periodismo de opinión significaría negar el proceso de conocimiento del tema político que inicia desde la conversión del acontecimiento en noticia, máxime cuando Agostini (1984) dispone una tipología de los casos en que puede originarse el fenómeno de la tematización: casos excepcionales (selección ideológica e irreflexiva propia de las rutinas periodísticas), grandes cuestiones de la vida colectiva (problemas económicos, culturales, de costumbres y morales) y las iniciativas de los periódicos para explorar ciertos temas.

En este sentido, Rodrigo Alsina (1989) reconoce que tanto en el primer como en el segundo punto, se está en presencia de información obligada, lo que corrobora que la información no puede ser ignorada al hablar de tematización.

\section{Estrategias ideológicas y discurso periodístico político}

Como se ha expresado, cada vez más la política se orienta a la mediatización (Kalb, 1992; Casero, 2009; Castells, 2009), por lo que es incuestionable que el discurso de la prensa mantiene una relación dinámica y dialéctica con el sistema político (Borrat, 1989; García Luis, 2013; Gallardo-Paúls y Enguix, 2014) y esto supone comprender aquel como "una enunciación de segundo nivel, dependiente del primer nivel generado por los actores políticos institucionales" (Gallardo-Paúls y Enguix, 2014).

La conversión del acontecimiento político en noticia supone aplicar complejas estrategias que abarcan desde la irrupción u ocurrencia del hecho, las ideologías profesionales de los periodistas y la línea editorial del medio que influyen en la intencionalidad periodística. Esta halla cuerpo en las formas ilocutivas, "actos de la conducta verbal humana lógicamente 
determinados y denominados también actos de habla" (Caballero, 2014: 11), cuyo fin es expresar los propósitos del periodista-medio-institución política. La taxonomía de actos de habla que propone Searle (1969) se basa en la que plantea Austin (1962) e incluye cinco tipos: representativos (representan un estado de cosas pasadas, futuras, presentes, concretas 0 hipotéticas), directivos (el emisor ordena), de compromiso (comprometen al receptor a realizar algo), expresivos (expresan el estado psicológico del emisor) y declarativos (realizan el estado de cosas expresados en el mismo acto).

Las intenciones con que se emiten los enunciados también incluyen a las presuposiciones y los sobreentendidos que generan (implicaciones). Según van Dijk (1997), la estrategia textual en la producción ideológica funciona en gran parte por "lo que está presente y ausente a un mismo tiempo" (p. 63), de ahí la importancia de las presuposiciones en la construcción del significado del texto periodístico por parte del lector, además de las relaciones de sinonimia, asociación, inferencia y sujeciones, que pueden ser elementos subyacentes a la ideología.

Singular relevancia adquiere por tanto la selección de las palabras, recurso que implícitamente se pone al servicio de la intencionalidad para la presentación positiva o negativa de determinada ideología. En el discurso periodístico la intención subyace en la elección de una unidad lingüística, y no otra, para designar determinado referente, a lo que Van Dijk (2004) agrega que al expresar conceptos, significados y "evaluaciones asociadas a dichos significados, la selección lexical es un medio obvio, y aún poderoso, para manejar las opiniones de los receptores tal como se presentan en los modelos mentales de los eventos".

A esto se unen las figuras retóricas, instancias fundamentales "de la construcción de significación, debido a que (...) constituyen un momento decisivo de la comunicación y son capaces de trastocar el orden de cualquier discurso" (Murillo, 2004: 370). Por ello se infiere que en el discurso periodístico la retórica utiliza "los dispositivos estratégicos que relacionan la veracidad, la plausibilidad, la corrección, la precisión y la credibilidad" (van Dijk, 1990: 138), en aras de que convenzan los aspectos relativos a la escritura o al habla.

Si se considera la visión de numerosos autores con relación a la esencia persuasiva de la prensa (van Dijk, 1990; Casado, 2008), debe destacarse que en su lenguaje se evidencia claramente el carácter argumentativo, sin exclusión de géneros. Así, el predominio de argumentos en las construcciones discursivas periodísticas tienen como fin acentuar o devaluar determinado tipo de informaciones, pues revelan "las repercusiones ideológicas, en tanto que son uno de los múltiples procedimientos (...) para construir una imagen concreta de determinados grupos sociales" (De la Fuente, 2006: 336).

Question, Vol. 1, N. ${ }^{\circ}$ 63, julio-septiembre 2019. ISSN 1669-6581

Instituto de Investigaciones en Comunicación | Facultad de Periodismo y Comunicación Social | Universidad Nacional de La Plata 
La argumentación, por tanto, se erige como una de las estrategias para obtener credibilidad, convencer y persuadir. Se trata de una práctica comunicativa destinada a lograr, mantener y renovar el consenso o reconocimiento intersubjetivo dentro de una comunidad y que tiene pretensiones de validez, legitimidad, eficacia, veracidad o inteligibilidad. Por tanto, como aseveran Calsamiglia y Tusón (1999: 295), la argumentación está ligada a la lógica de la experiencia, que a su vez lo está a un mundo de valores axiológicos y de creencias, a una ideología dependiente de una cultura de cada grupo sociocultural, donde cobra similitud.

Mediante el empleo de estrategias argumentativas el discurso periodístico sobre política se sustenta en referentes ideológicos que pueden ser aportados tanto por las fuentes de información en los que se basa (argumentos de autoridad), el modo en que el discurso periodístico se hace eco del discurso emitido por los actores políticos institucionales (intertextualidad), o la autopresentación positiva de Nosotros (grupo afín a la ideología del medio) y la presentación negativa de Ellos (grupo contrario), rivalidad que van Dijk (1996) asegura palpable en el discurso ideológico. De esta manera siempre se ocultarán o mitigarán las acciones positivas de Ellos. Los actos negativos de los otros pueden ser enfatizados con hipérboles, descripciones concretas y detalladas, advertencias y escenarios condenatorios.

Esta estrategia de representación ideológica es considerada regla general dentro del discurso político. Basado en ella, van Dijk (2005) propone cuatro estrategias globales, aplicables a todos los niveles de acción del discurso, incluido el periodístico, en lo que llama "cuadrado ideológico", compuesto por las siguientes aristas: enfatizar en nuestras/sus cosas buenas/malas y minimizar nuestras/sus cosas malas/buenas.

Siendo un objetivo del discurso periodístico que se construye sobre temas políticos en todas sus manifestaciones (emisiones por actores políticos o medios de comunicación) el énfasis en nuestras cosas buenas y sus cosas malas, se predecirá que las acciones de Nosotros, en el caso de los diarios, aparecerán en primera plana, en la parte superior de una página o con mayor tamaño; en cuanto a la televisión o la radio, en el primer lugar de un programa; y será primer tema de un discurso emitido por una figura política importante. Lo mismo ocurrirá con los actos negativos de Ellos.

Desde esta línea de reflexión resulta pertinente destacar los modos de operación de la ideología en el discurso que esboza Thompson (1993), y las formas en que estos pueden vincularse con ciertas maneras de construcción simbólicas. Este estudio suscribe el criterio de Gutiérrez (2002), quien asegura que aún "queda por realizarse una investigación más profunda sobre la manera en que la ideología opera en condiciones sociohistóricas específicas". Así, 
Thompson (1993) distingue: la legitimación, la simulación, la unificación, la fragmentación y la cosificación.

Con la legitimación, considera que las relaciones de dominación ideológica que ejerce un grupo social sobre otro se pueden ver como justas, al punto de demandar apoyo. La simulación se evidencia al ocultar, negar o disimular relaciones de dominación al presentar los hechos, de modo que quede desviada la atención de los públicos o se oculten las relaciones existentes.

La unificación tiene en cuenta la identidad colectiva de una comunidad de individuos, sin considerar sus posibles diferencias. La fragmentación tiene lugar cuando los individuos de un colectivo o una sociedad se organizan o no en grupos que podrían desafiar a las élites dominantes de manera efectiva u orientarse opuestamente a un objetivo que se proyecta como maligno, dañino o amenazador. Con la cosificación se representa un estado de cosas histórico y transitorio como si fuese permanente, natural e intemporal para establecer relaciones de dominación.

\section{A modo de conclusiones}

La construcción del discurso periodístico no sólo depende de una mera rutina, sino es un proceso variado, basado en las propias lógicas de las organizaciones periodísticas, signado por la mediación de procedimientos para controlar y legitimar la transmisión de significados, con el complejo de prácticas que supone, reproduce las relaciones presentes en la sociedad, al tiempo que el emisor estampa su subjetividad, que puede entenderse como o bien del periodista o del bien medio que representa. A través de este tipo de discurso se construye el escenario social, mediado por subjetividades y puede ser analizado tomando en cuenta sus estrategias.

El discurso periodístico se inserta en uno de tipo mayor, el mediático, estrechamente vinculado al poder político. En periodo de elecciones, las cargas semánticas y de significados de los mensajes mediáticos buscan deslegitimar a determinados sectores, en función de sus intereses y elaborando manifiestos donde plasman sus ideologías. Así, el carácter discursivo e ideológico 
del fenómeno de la política es principalmente reproducido por el texto y por el habla, encontrando en el periodismo una forma segura de difusión.

A esto se suma que en tanto segundo nivel de enunciación, el discurso periodístico que produce y reproduce temas políticos, exige ser investigado desde un enfoque multifacético y de compromiso social que dé cuenta de las intencionalidades que operan a nivel simbólico.

Notas

(1) Esas etapas por las que atraviesa el discurso periodístico, señalan su inserción dentro del marco de un sistema productivo, con el fin de comunicar, informar y exponer ideas, usando a los medios de comunicación como canal.

\section{Bibliografía}

Agostini, A. (1984). La tematización. Selección y memoria de la información periodística. Problema de la información, 9(4), 531-560.

Artenton, C. (1987). Las estrategias informativas de las campañas presidenciales. La política de los medios de información. México D. F, México: Publigrafics.

Austin, J. L. (1962). Cómo decir cosas con palabras. Oxford, United Kingdom: Clarendon Press.

Badía, L. (1992). De la persuasió a la tematizació. Introducció a la comunicació política moderna. Barcelona, España: Pórtic.

Beaudoux, V. G. y D'Adamo, O. (2004). Campañas electorales y sus efectos sobre el voto. Análisis de la campaña electoral presidencial 2003 en Argentina. Psicología Política, 28, 7-25.

Borrat, H. (1989). El periódico, actor político. Análisis, 12, 67-80. 
Brussino, S.; Paz García, A. P.; Rabbia, H. e Imhoff, D. (2011). Ideología Política y prácticas mediatizadas de consumo informativo. Debates, 5(2), 13-40.

Caballero Díaz, L. (2014). Semántica y Diccionario. La Habana, Cuba: Ciencias Sociales.

Calsamiglia, H. y Tusón Valls, A. (1999). Las cosas del decir. Manual de análisis del discurso. Barcelona, España: Ariel.

Calzadilla, I. (2012). La nota: de informar a explicar. Estudio acerca del empleo de la nota interpretativa en los medios de comunicación impresos cubanos Granma y Trabajadores. (Tesis de doctorado). Facultad de Comunicación, Universidad de La Habana, Cuba.

Casado Velarde, M. (2008). Algunas estrategias discursivas en el lenguaje periodístico de hoy. Boletín Hispánico Helvético, 12, 71-97.

Casero Ripollés, A. (2009). Modelos de relación entre periodistas y políticos: la perspectiva de la negociación constante. Estudios sobre el mensaje periodístico, 14, 111-128.

Castells, M. (2009). Comunicación y poder. Madrid, España: Alianza Editorial.

Champagne, P. (2000). La visión mediática. En Bourdieu, P. La miseria del mundo (2a edición) (pp. 5163). Buenos Aires, Argentina: FCE.

Chavero, P.; González, J. J.; Bouza, F.; Castromil, A. y Rodríguez, R. (2013). La mediatización de la agenda política: la discusión del pacto social como conflicto de agendas, 2009-2011. Revista Latina de Comunicación Social, 68. Recuperado de http://www.revistalatinacs.org/068/paper/994_Complutense/28_Palmira.html

Dader, J. L. (1990). La canalización o fijación de la "agenda" por los medios. En Muñoz Alonso, A. I.; Rospir, J.; Dader J. L. y Monzón, C. (Ed). Opinión pública y comunicación política (pp. 294318). Madrid, España: Eudema Universidad.

De Fontcuberta, M. (1990). La Noticia. Pistas para percibir el mundo. Barcelona, España: Paidós.

De la Fuente García, M. (2006). La argumentación en el discurso periodístico sobre la inmigración (Tesis de doctorado). Facultad de Filosofía y Letras, Universidad de León, España.

De Moragas, M. (1979). Sociología de la comunicación de masas. Barcelona, España: Gustavo Gili. 
Ellis, C. y Stimson J. (2005). Operational and symbolic ideology in the American electorate: the paradox revisited. Memories of Annual Meeting of the Midwest Political Science Assotiation, 63, 1-57.

Fara, C. (2004). Comunicación política en América Latina: tendencias, factores y problemas prácticos. Diálogo Político, 21(1), 79-99.

Gallardo-Páuls, B. y Enguix, S. (2014). Estrategias de Encuadre Discursivo en Periodismo Político: Análisis de un Corpus de Titulares. Círculo de Lingüística Aplicada a la Comunicación, 58, 90109.

García Delgado, D. (1998). Crisis de representación en la Argentina de fin de siglo. En Isuani, A.y Filmus, D. (Eds). La Argentina que viene. Análisis y propuestas de una sociedad en transición (pp. 367-380). Buenos Aires, Argentina: FLACSO-NORMA.

García Luis, J. (2013). Revolución, Socialismo, Periodismo. La prensa y los periodistas cubanos ante el siglo XXI. La Habana, Cuba: Pablo de la Torriente.

Genro Filho, A. (2010). El secreto de la pirámide. Caracas, Venezuela: Agencia Bolivariana de Noticias.

Gutiérrez Vidrio, S. (2002). El uso de algunas estrategias discursivas en el discurso político. En Machado Rodríguez, D. L. (Ed.). Introducción al análisis ideológico del contenido del discurso (pp 90-104). La Habana, Cuba: Pablo de la Torriente.

Grossi, G. (1985). La Comunicación Política Moderna: entre partidos de masa y "mass media". En de Moragas, M. (Ed.). Sociología de la Comunicación de Masas, IV. Nuevos problemas y transformación tecnológica (pp 144-164). Barcelona, España: Gustavo Gili.

lyengar, S. y Kinder, D. (1987). News That Matters. Chicago, United States: University of Chicago Press.

lyengar, S. y Simon, A. (1993). News coverage of the gulf crisis and public opinion. Communication Research, 34, 365-383.

Kalb, M. (1992). Press-Politics and Improving the Public Dialogue. Political Communication Report, 3, 13.

Krosnick, J. y Kinder, D. (1990). Altering the foundations of presidential support through priming. American Political Science Review, 84, 497-512. 
Lazarsfeld, P. y Berelson, B. (1944). The People's Choice: How the Voter Makes Up His Mind in a Presidential Campaign. New York, United States: Columbia University Press.

López-Escobar, E.; Llamas, J. P. y McCombs, M. (1996). Una dimensión social de los efectos de los medios de difusión: agenda-setting y consenso. Comunicación y Sociedad, IX(1-2), 91-125.

Luhmann, N. (1975). El Plano Político. Stturgart: Opladen.

Luhmann, N. (1978). Offentliche Meinung. Politische Vierteljahresschrift, XI, 2-28.

Luhmann, N. (2000). La realidad de los medios de masas. México: Ántropos.

Manin, B. (1998). Los principios del gobierno representativo. Madrid, España: Alianza.

Mazzoleni, G. (1998). La comunicación política. Madrid: Alianza Editorial.

McCombs, M. y Evatt, D. (1995). Los temas y los aspectos: explorando una nueva dimensión de la agenda-setting. Comunicación y Sociedad, 8, 7-32.

McCombs, M. y Shaw, D. (1972). The agenda setting function of the media. Public Opinion Quarterly, 36, 176-187.

McCombs, M. (1996). Influencia de las noticias sobre nuestras imágenes del mundo. En Bryant, J. y Zillmann, D. (Ed.). Los efectos de los medios de comunicación. Investigaciones y teorías (pp. 13-34), Barcelona, España: Paidós.

McCombs, M. (2006). Estableciendo la agenda. El impacto de los medios en la opinión pública y en el conocimiento. Barcelona, España: Paidós Comunicación.

Moreno García, A. (2007). Un proyecto de medición del nivel de aceptación de la ideología de los grupos dominantes. Discurso y Sociedad, 1(3), 482-511.

Murillo, O. (2004). Análisis del discurso social. Investigaciones sociales, 13, 369-385.

Noelle-Neumann, E. (1995). La espiral del silencio. Opinión Pública: nuestra piel social. Barcelona, España: Paidós.

Ricardo, R. (2012). El magnicidio mediático de Hugo Chávez. El caso del diario El Nacional durante la campaña por la Enmienda Constitucional de 2009. (Tesis de Doctorado). Universidad de La Habana, Facultad de Comunicación, Cuba. 
Rincón, O. (2010). ¿Por qué nos odian tanto? Estado y Medios de Comunicación en América Latina. Bogotá, Colombia: Centro de Competencia en Comunicación para América Latina.

Roda Fernández, R. (1989). Medios de comunicación de masas. Su influencia en la sociedad y en la cultura contemporánea. Madrid, España: Centro de Investigaciones Sociológicas.

Rodrigo Alsina, M. (1989). La construcción de la noticia. Barcelona, España: Paidós.

Rodrigo Alsina, M. (2005). La Construcción de la Noticia. Nueva edición revisada y ampliada. Barcelona, España: Paidós Comunicación.

Rodríguez Betancourt, M. (2004). Géneros periodísticos: para arropar su hibridez. Estudios sobre el mensaje periodístico, 10, 319-328. Recuperado de https://bit.ly/2mrutfl

Rondoletto, M. (2001). Sujeto y discurso periodístico. Cuadernos, 17, 403-414.

Rositi, F. (1980). Historia y teoría de la cultura de masas. Barcelona, España: Gustavo Gili.

Rositi, F. (1982). El modo de la argumentación y la opinión pública. Torino, Italia: ERI-RAI.

Santillán Buelna, J. R. (2005). Political issue, un ejemplo de tematización periodística. Cómo los problemas públicos se seleccionan, discuten y solucionan en la prensa de referencia. Recuperado de http://www.aeic2010malaga.org/upload/ok/220.pdf

Saperas, E. (1987). Los efectos cognitivos de la comunicación de masas. Barcelona, España: Ariel.

Sartori, G. (1992). Elementos de Teoría Política. Madrid, España: Alianza Universidad.

Searle, J. R. (1969). Actos de habla. Cambridge, United Kingdom: University Press.

Thompson, J. B. (1993). Ideología y cultura moderna. Teoría y crítica social en la era de la comunicación de masas. Xochimilco, México: Ed. Universidad Autónoma Metropolitana.

Túñez, M. y Guevara, M. (2009). Framing por proximidad como criterio de noticiabilidad: la curva de las ausencias. Revista Latina de Comunicación Social, 64, pp. 1030-1044. doi: 10.4185/RLCS-642009-878-1.030-1.044

van Dijk, T. (1990). La noticia como discurso. Barcelona, España: Paidós Comunicación.

van Dijk, T. (1996). Opiniones e ideología en la prensa. Revista Voces y Cultura, 10, pp. 9-50. Recuperado de dialnet.unirioja.es/servlet/extaut?codigo=273292 
van Dijk, T. (1997). El discurso como interacción social. Estudios sobre el discurso II. Introducción multidisciplinaria. Barcelona, España: Gedisa.

van Dijk, T. (2003). La multidisciplinaridad del análisis crítico del discurso: un alegato a favor de la diversidad. En Wodak, R. y Meyer, M. (Ed.). Métodos de análisis crítico del discurso (pp. 143177). Barcelona, España: Gedisa.

van Dijk, T. (2005). Política, ideología y discurso. Quórum Académico, 2(2). Recuperado de www.discursos.org/oldarticles/Politica\%20ideologia.pdf

Verón, E. (1993). La semiosis social. Fragmentos de una teoría de la discursividad. Barcelona: Editorial Gedisa.

Waisbord, S. (1995). Knocking on newsroom doors: press and political scandals in Argentina. Political Communication, 11(1), 19-33.

Wolf, M. (2000). La investigación de la comunicación de masas. La Habana, Cuba: Pablo de la Torriente.

Wolf, M. (2002). Los emisores de noticias en la investigación sobre comunicación. Cuadernos Digitales, 15, Recuperado de www.quadernsdigitals.net/books/zer/zer3/z3emisores.html 